Research Article

\title{
Synthesis of Magnetic Catalyst Derived from Oil Palm Empty Fruit Bunch for Esterification of Oleic Acid: An Optimization Study
}

\author{
Shamala Gowri Krishnan', Fei-Ling Pua ${ }^{2,3, *}$, Ee-Sann Tan ${ }^{2,3}$
}

${ }^{1}$ College of Graduate Studies, Universiti Tenaga Nasional, 43000 Kajang, Selangor, Malaysia.

${ }_{2}^{2}$ Institute of Sustainable Energy, Universiti Tenaga Nasional, 43000 Kajang, Selangor, Malaysia. ${ }^{3}$ Department of Mechanical Engineering, College of Engineering, Universiti Tenaga Nasional, 43000 Kajang, Selangor, Malaysia.

Received: 30th September 2021; Revised: 18 ${ }^{\text {th }}$ November 2021; Accepted: $18^{\text {th }}$ November 2021 Available online: 22 nd November 2021; Published regularly: March 2022

\section{Abstract}

Biomass, renewable, abundantly available and a good source of energy. The conversion of biomass waste into valuable products has received wide attention. In this study, an empty fruit bunch (oil palm EFB) supported magnetic acid catalyst for esterification reaction was successfully prepared via the one-step impregnation process. The new magnetic catalyst achieved a higher surface area of $188.87 \mathrm{~m}^{2} / \mathrm{g}$ with a total acidity of $2.4 \mathrm{mmol} / \mathrm{g}$ and identified iron oxide as $\gamma-\mathrm{Fe}_{2} \mathrm{O}_{3}$. The magnetization value of $24.97 \mathrm{emu} / \mathrm{g}$ demonstrated that the superparamagnetic catalyst could be easily recovered and separated after the reaction using an external magnet. The catalytic performance of oil palm EFB supported magnetic acid catalyst was examined by esterification of oleic acid. Esterification process parameters were optimized via Response Surface Methodology (RSM) optimization tool with Box-Behnken design (BBD). The following optimum parameters were determined: an amount of $9 \mathrm{wt} \%$ catalyst, molar ratio of methanol to oleic acid of $12: 1$, reaction time of $2 \mathrm{~h}$ and reaction temperature of $60{ }^{\circ} \mathrm{C}$ with a maximum conversion of $94.91 \%$ was achieved. The catalyst can be recycled up to five cycles with minimal loss in its activity. The oil palm wastebased magnetic acid catalyst indicates its potential replacement to the existing solid catalysts that are economical and environmentally friendly for the esterification process in biofuel applications.

Copyright (C) 2021 by Authors, Published by BCREC Group. This is an open access article under the CC BY-SA License (https://creativecommons.org/licenses/by-sa/4.0).

Keywords: Biomass; Magnetic; Catalyst; Esterification; Optimization; Oil Palm Empty Fruit Bunch

How to Cite: S.G. Krishnan, F.-L. Pua, E.-S. Tan (2022). Synthesis of Magnetic Catalyst Derived from Oil Palm Empty Fruit Bunch for Esterification of Oleic Acid: An Optimization Study. Bulletin of Chemical Reaction Engineering \& Catalysis, 17(1), 65-77 (doi: 10.9767/bcrec.17.1.12392.65-77)

\section{Introduction}

Biomass is an organic material derived from plant-based resources [1]. Biomass is utilized as a clean energy source to reduce fossil-based fuel usage problems, which also helps reduce the global energy crises [2]. Besides, biomass has a

\footnotetext{
* Corresponding Author.

Email: gracepua@uniten.edu.my (F.-L. Pua);

Telp: +603-89212020
}

great renewable energy source and contributes around $14 \%$ of global renewable production [3]. The lignocellulosic components cellulose, hemicellulose, and lignin are abundant in lignocellulosic biomass. Oil palm, paddy, Kenaf, rubber and cocoa are the among major crops found in Malaysia. A large amount of waste being generated from Oil palm mills, such as empty fruit bunch (EFB), palm kernel shells and oil palm trunks [4]. Oil palm EFB is one of the waste products of oil palm fresh fruit after oil extrac- 
tion. Traditionally, EFB is utilized as boiler fuel; however, unwanted smoke emission and ash formation draw a limitation to the usage of EFB [5]. Although EFB is abundantly available, only a limited amount was used as waste recycling, and others were left in the plantation to decompose.

Due to the extreme utilization of fossil fuels, researchers are driven to develop an alternative fuel to replace depleting conventional fuels. Biodiesel is renewable energy produced from edible oils serves as an environmentally friendly, non-toxic and biodegradable fuel [6]. Either esterification, transesterification or both produce biodiesel with oil-based feedstock, alcohol and catalyst. Biodiesel is commonly known as fatty acid methyl ester (FAME). Feedstock with low free fatty acid (FFA) is essential for biodiesel production by transesterification reaction with a base catalyst [7]. Due to the high consumption of edible oils in the food industry, the utilization of non-edible oil has drawn the attention of researchers. However, non-edible oils contain high FFA content, which requires two steps to produce biodiesel, where esterification involves an acid-catalyzed reaction followed by the transesterification reaction [8]. Esterification reaction involves reducing FFA in non-edible oils using an acid catalyst and alcohol to produce alkyl ester with lower FFA content. FFA of less than $<1 \%$ is required as high FFA content leads to soap formation due to the interaction of base catalyst in transesterification reaction [9]. Hence, acid-catalyzed esterification is required for non-edible oil before transesterification.

Catalyst is an additive chemical that accelerates a chemical reaction to produce the desired products. In the biodiesel industry, sulfuric acid, phosphoric acid, sodium hydroxide, and potassium hydroxide catalysts were widely utilised [10]. Homogeneous catalyst referred to as liquid catalyst that exists in the same state as reactants and products. Despite its fast reaction, the homogeneous catalyst limits its recovery from the reaction mixture. It requires product purification, which produces much wastewater and equipment corrosion, leading to increased production costs [11]. Hence, the use of heterogeneous was initiated in biodiesel production as it does not dissolve in reactants and products, reusable, high activity and selectivity. Heterogeneous catalysts are produced by synthesising chemical particles on the support material. The commercially available support materials include heteropoly acids, ion exchange resins, sulfonated metal oxides, zirconia and zeolite solids [12]. However, the use of those support materials essentially affects the catalyst production cost. Therefore, the biomass-based support material can replace conventionally available materials, especially agricultural waste [13]. The carbonaceous solid acid catalysts possess carboxylic $(-\mathrm{COOH})$ and hydroxyl groups $(-\mathrm{OH})$. Meanwhile, the sulfonic group $\left(-\mathrm{SO}_{3} \mathrm{H}\right)$ can be functionalized by direct sulfonation, and it has been the most extensively studied method for the preparation of carbonaceous solid acid catalysts. However, sulfated carbon-based catalysts using sulfuric acid have weak acidity and poor recyclability due to sulfate ion leaching $\left(\mathrm{SO}_{4}{ }^{2-}\right)$ [14]. Besides, separation of these solid acid catalysts from the reaction mixture often requires filtration and centrifugation. Although the separation processes are not complex, it needs extra effort to separate the catalysts from the mixture and retain catalysts catalytic activities.

Magnetic catalyst has excellent advantages in ease and quick separation, overcoming catalyst separation problem from the reaction. Therefore, incorporating magnetic properties into the biomass-based catalysts would be essential to assist rapid separation and avoid loss of catalyst post-reaction. Incorporating magnetic particles and iron oxide $(\mathrm{Fe}-\mathrm{O})$ into the catalyst can be a promising approach to accelerate the esterification reaction. It was mentioned that $\mathrm{Fe}-\mathrm{O}$ acts as Lewis acid and promote good catalytic activity [15]. Recently, studies on the magnetic derived catalysts have increased due to their high surface area and simple separation method, which can be recovered using a magnet. Based on the previous studies, a sulfated magnetic carbon-based solid acid (C-SO $\left.{ }_{3} \mathrm{H} @ \mathrm{Fe} / \mathrm{JHC}\right)$ catalyst was developed from Jatropha-hull hydrolysate to produce Jatropha biodiesel, and it has exhibited high catalytic activity of $92.44 \%$ with a magnetization value of $11.2 \mathrm{Am}^{2} / \mathrm{kg}$ [16]. A nano-sized magnetic catalyst $\mathrm{KF} / \mathrm{CaO}-\mathrm{Fe}_{3} \mathrm{O}_{4}$, was synthesized by $\mathrm{Hu}$ et al. [17] for biodiesel production with more than $95 \%$ yield at optimized reaction conditions. The application of heterogenous magnetic catalysts from biomass is an attention for research. It was noted that the preparation of magnetic acid catalysts involves multiple preparation steps and uses expensive chemicals, which consequently create problems in the catalyst synthesis and prevent largescale production [18]. Thus, introducing environmentally safe support materials in catalyst synthesis could widen the applicability of biomass. Besides, investigating the catalyst synthesis by determining the appropriate preparation steps and has minimal waste production. 
This research aims to synthesize and characterize oil palm EFB fiber supported magnetic solid acid catalyst and examine its catalytic activity. The synthesised catalyst analysed by scanning electron microscopy (SEM), energydispersive X-ray spectroscopy (EDX), Brunauer-Emmett-Teller (BET), X-ray powder diffraction (XRD), vibrating sample magnetometry (VSM), Fourier transform infrared spectroscopy (FT-IR) and acid density test. The BoxBehnken optimization design was employed for esterification reaction to evaluate the impact of catalyst loading, methanol to oleic acid molar ratio and reaction time on esterification rate. Furthermore, the reusability of the synthesized catalyst was investigated to determine its potential in the esterification reaction.

\section{Materials and Methods}

\subsection{Materials}

Oil palm EFB fiber purchased from Sztech Engineering Sdn. Bhd. (Selangor, Malaysia). Analytical chemicals, Ferric sulphate, 99\% $\left(\mathrm{Fe}_{3}\left(\mathrm{SO}_{4}\right)_{2}\right)$, ferrous sulphate heptahydrate, $98 \%\left(\mathrm{FeSO}_{4} .7 \mathrm{H}_{2} \mathrm{O}\right)$ and sodium bicarbonate, $99.5 \%\left(\mathrm{Na}_{2} \mathrm{CO}_{3}\right)$ powders utilized in the catalyst synthesis were supplied from Suria Pembekal Umum Sdn. Bhd (Malaysia). For the esterification process, industrial oleic acid, 99\% (acid value of $199 \mathrm{mg} \mathrm{KOH} / \mathrm{g}$ ) (R\&M, Malaysia) was utilized as the raw material.

\subsection{Catalyst preparation}

The one-step impregnation approach was used to synthesize the EFB-magnetic solid acid catalyst. EFB fibers were pre-treated with 0.1 $\mathrm{M} \mathrm{Na}_{2} \mathrm{CO}_{3}$ solution for $1 \mathrm{~h}$ at room temperature with a solid to liquid ratio of $1: 10$. The treated EFB fibers were then washed with distilled water to eliminate the remaining $\mathrm{Na}_{2} \mathrm{CO}_{3}$. The treated EFB fibers were oven-dried at $105{ }^{\circ} \mathrm{C}$ overnight and were utilized for catalyst preparation. The treated EFB fibers were impregnated by mixing the fibers in a solution of $\mathrm{FeSO}_{4} .7 \mathrm{H}_{2} \mathrm{O}$ and $\mathrm{Fe}_{3}\left(\mathrm{SO}_{4}\right)_{2}$ with a chemical ratio of $1: 2$ and thorough stirring at $60^{\circ} \mathrm{C}$. A solid-to-liquid ratio of 1:10 was used, and the impregnated sample was oven-dried for 24 hours at $80{ }^{\circ} \mathrm{C}$. A vacuum furnace was used to calcine the dried sample at $500{ }^{\circ} \mathrm{C}$ for $2 \mathrm{~h}$ with a heating rate increase of $10{ }^{\circ} \mathrm{C} / \mathrm{min}$. The EFBmagnetic acid catalyst is denoted as $\mathrm{EFB}_{\mathrm{MAC}}$.

\subsection{Catalyst Characterization}

The physicochemical properties of $\mathrm{EFB}_{\mathrm{MAC}}$ were analyzed. The morphologies and ele- mental content of the catalyst were determined using scanning electron microscopy (SEM) with electron dispersive X-ray spectroscopy (EDX) (JSM-6010PLUS/LV, Universiti Tenaga Nasional). The structural composition and pattern were identified using X'Pert Pro, PANalytical X-ray diffraction (XRD) (Quantum Skynet) with a scanning range from $10-90^{\circ}$ and $\mathrm{Cu} \mathrm{K \alpha}$ radiation of $\lambda=0.154 \mathrm{~nm}$. The specific surface area and pore volume were measured using Brunauer-Emmett-Teller (BET) analysis with Micromeritics, Model: ASAP2020, USA (Quantum Skynet) by $\mathrm{N}_{2}$ adsorptiondesorption. Fourier transform infrared spectroscopy (FT-IR; Nicolet iS10, Thermo Fisher Scientific Co., Ltd., Waltham, MA) with a frequency range of $4000400 \mathrm{~cm}^{-1}$ was used to identify the catalyst's functional groups. A vibrating sample magnetometer (VSM) (Lake Shore 7400 Series) at Nanocat Lab, Universiti Malaya, was used to examine the catalyst's magnetic property. The catalyst acidity was measured by the acid-base titration method with sodium hydroxide solution $(0.1 \mathrm{M})$ as titrant.

\subsection{Catalytic Performance}

\subsubsection{Esterification reaction}

The esterification reaction over the EFBMAC catalyst was investigated using a $100 \mathrm{ml}$ flat bottom three neck-flask with a conventional reflux system. The experiment was carried out using oleic acid and methanol as the primary reactants. EFB $\mathrm{MAC}$ catalyst was mixed with oleic acid and methanol at fixed reaction temperature and reaction speed of $60{ }^{\circ} \mathrm{C}$ and $350 \mathrm{rpm}$, respectively. The used catalyst was recovered using a magnet post of the reaction. The recovered catalyst was washed with ethanol and oven-dried overnight for consecutive esterification reactions to investigate its reusability. The esterification conversion was evaluated based on Equation (1) and (2) [19].

$$
\begin{aligned}
& \text { Acid value }=\frac{V \times[c] \times 56.1}{g} \\
& \text { Esterification rate }=\left(\frac{A V_{0}-A V_{f}}{A V_{0}}\right) \times 100
\end{aligned}
$$

where, $V$ is volume of titrant consumed $(\mathrm{ml})$, 56.1 is molar mass of $\mathrm{KOH}$, [c] is concentration of titrant used, $A V_{o}$ and $A V_{f}$ are the initial acid value of oleic acid and esterified samples, respectively. 


\subsubsection{Optimization (Box-Behnken)}

The Box-Behnken technique was used to optimize three independent variables: catalyst loading (A), the methanol-to-oleic acid molar ratio (B), and duration $(\mathrm{C})$. Based on the literature study [20-22] and preliminary experimental results, the range of variables was determined. The range of experimental values used is $5-9$ wt\% catalyst loading, 8:1-12:1 methanol to oleic acid molar ratio and 90-150 min. The experimental data for optimization of esterification reaction were extracted from Design Expert Software (version 10.0.3), and the esterification rate as a response was determined to analyze the data. The responses of the randomized experiments were correlated with the variables using a full quadratic model (Equation (3)):

$$
Y=\beta_{0}+\sum_{i=1}^{3} \beta_{i} x_{i}+\sum_{i=1}^{3} \beta_{i i} x_{i}^{2}+\sum_{i=1}^{2} \sum_{j=i+1}^{3} \beta_{i j} x_{i j}+\varepsilon
$$
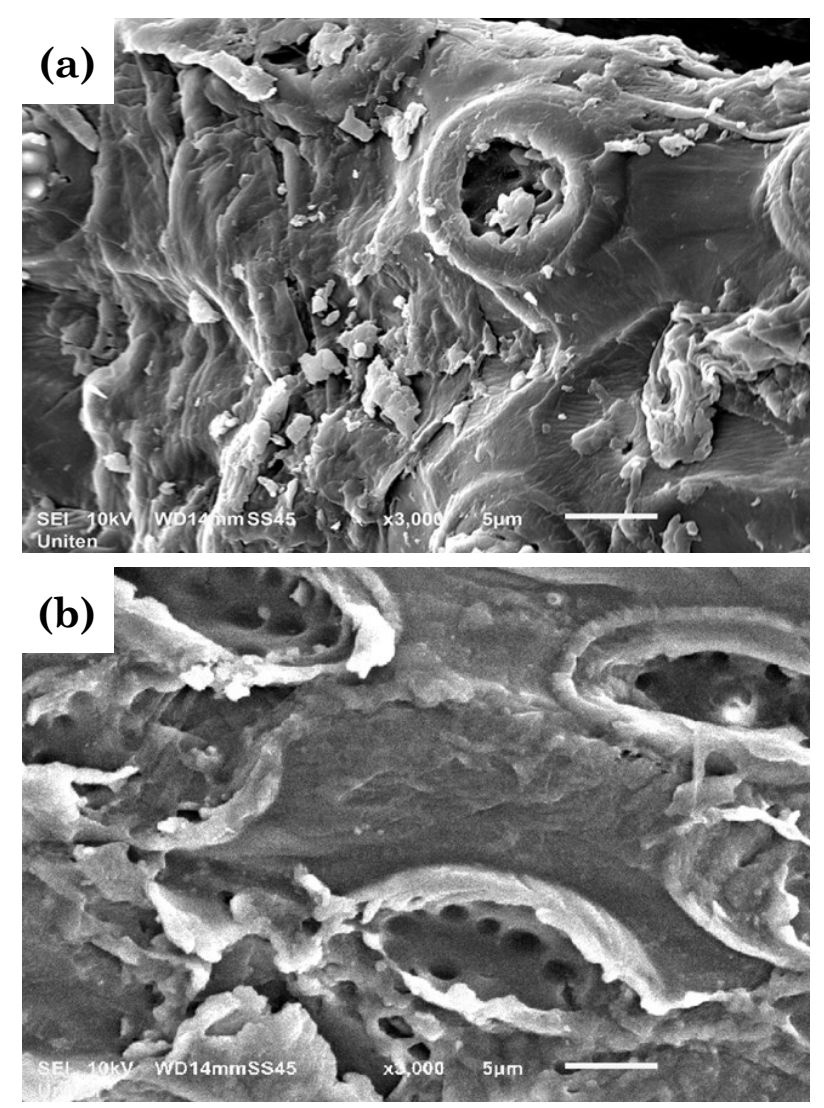

where, $Y$ is the response, $\beta_{0}$ is the regression coefficient for the intercept, $\beta_{i}$ is the regression coefficient for the linear term, $\beta_{i i}$ is the regression coefficient for the quadratic term, and $\beta_{i j}$ is the regression coefficient for the interactive term, $x_{i}$ and $x_{j}$ are independent variables and, $\varepsilon$ is the error. Table 1 presents the independent variables and the ranges used in the

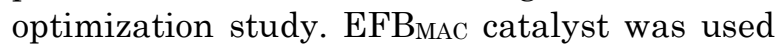
to evaluate its catalytic performance on the esterification of oleic acid.

\section{Results and Discussion}

\subsection{Acid Density Test}

The $\mathrm{NaOH}$ titration technique was used to measure the acidity of EFB MAC. The catalyst had the highest acidity of $2.4 \mathrm{mmol} / \mathrm{g}$, which indicates the presence of the sulfonic acid $\left(-\mathrm{SO}_{3} \mathrm{H}\right)$ groups in the catalyst [23]. A study on synthesis of heterogeneous acid catalyst from corncob for esterification of oleic acid was conducted by Dechakhumwat et al. [24]. The catalyst exhibited an acidity of $0.58 \mathrm{mmol} / \mathrm{g}$ using $\mathrm{Ts} \mathrm{OH}$ as sulfonating agent. Meanwhile, a magnetic mesoporous carbon sphere catalyst was fabricated by Chang et al. [25]. The solid catalyst had an acidity of $1.73 \mathrm{mmol} / \mathrm{g}$, showed a good catalytic performance for the production of methyl oleate. Thus, the high acidity of EF$\mathrm{B}_{\mathrm{MAC}}$ derived from local biomass could enhance the catalytic activity during the esterification reaction.

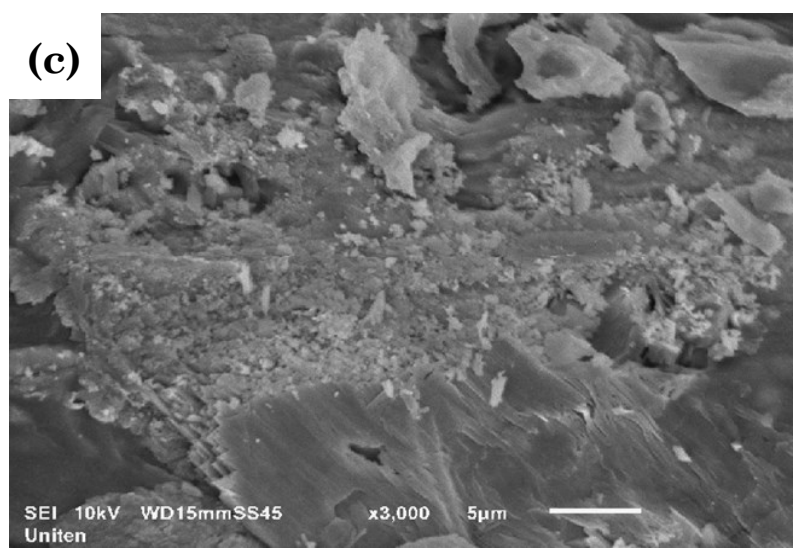

Figure 1. SEM images of (a) untreated EFB fibers, (b) alkaline treated EFB fibers and (c) EFBMAC calcined after $500^{\circ} \mathrm{C}$.

Table 1. The variables and ranges for optimization study using Box-Behnken method.

\begin{tabular}{lcccc}
\hline Variables & Symbol & -1 & 0 & +1 \\
\hline Catalyst loading (\%) & $\mathrm{A}$ & 5 & 7 & 9 \\
Methanol to oleic acid molar ratio & $\mathrm{B}$ & $8: 1$ & $10: 1$ & $12: 1$ \\
Duration (min) & $\mathrm{C}$ & 90 & 120 & 150 \\
\hline
\end{tabular}




\subsection{Morphology Analysis}

Figure 1 demonstrates the SEM images of untreated EFB fibers, delignified EFB fibers, and $\mathrm{EFB}_{\mathrm{MAC}}$ catalyst. The fiber's outer layer is made up of lignin, which prevents it from rupturing (Figure 1(a)). As observed, silica bodies were discovered embedded on the fiber surfaces and substances such as oil and impurities that covered the surface. This result was comparable to the findings of Ibrahim et al. that reported the presence of silica bodies on the surface of untreated fibers $[26,27]$. The alkaline treatment substantially changed the morphology of the fibers (Figure 1(b)). The lignin-based outer layer was removed through chemical treatment by debonding the linkages of the outer surface. It was observed that the silica bodies were removed after being treated with $0.1 \mathrm{M} \mathrm{Na}_{2} \mathrm{CO}_{3}$ and allow the appearance of pores on the fiber surface. Previous studies showed that surface roughness results in better adhesion ability of fiber with particles [28]. Figure 1(c) shows the pores of treated EFB fibers were embedded with particles and made the surface much coarser. After calcining at $500{ }^{\circ} \mathrm{C}$, the magnetic $(\mathrm{Fe}-\mathrm{O})$ and sulfated $\left(\mathrm{SO}_{4}{ }^{2-}\right)$ particles were fixed on the carbon skeleton. Thus, the pretreatment has exposed the pores on the fibers' surface and allows particles to adhere to it.

\subsection{Elemental Analysis}

EDX analyzed the surface chemical contents of treated EFB fiber and EFBMAC. Table 2 shows that treated EFB fiber mainly consisted

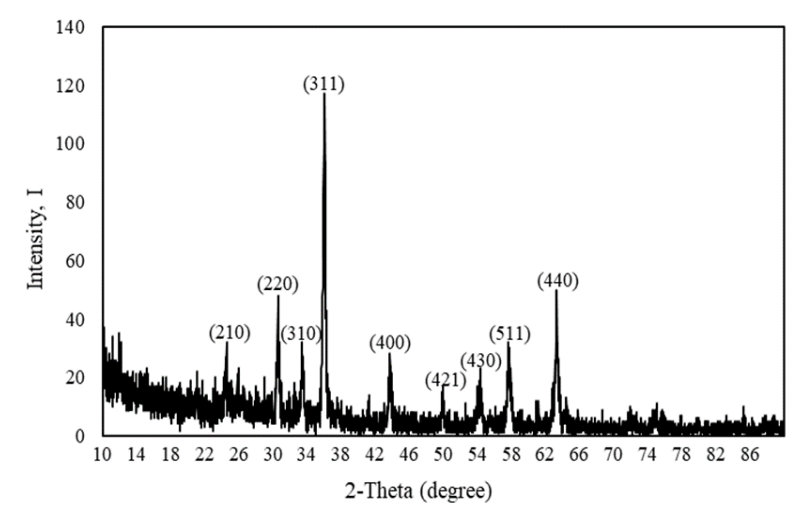

Figure 2. X-ray diffraction pattern of EFBMAC catalyst. of carbon (57.76\%) and oxygen (42.24\%). The analysis indicated that silica $\left(\mathrm{SiO}_{2}\right)$ was not observed on the EFB surface post pretreatment process. The pretreatment process successfully removed the silica bodies and impurities. This result was similar to the results reported by [29], where the pretreatment process removed the silicified waxy layer from the fiber surface. After impregnation, the carbon and oxygen content decreased to $37.88 \%$ and $34.78 \%$, respectively, due to the increased composition of iron and sulfur to $21.82 \%$ and $5.52 \%$, respectively (Table 2) This shows that the surface of the treated EFB fiber was impregnated with ferric sulphate. The acidity in the EFB MAC $_{\text {cat- }}$ alyst is corresponded to the increase in sulfur content and remarks the existence of sulfonic groups $\left(-\mathrm{SO}_{3} \mathrm{H}\right)$. The high acidity catalyst could be a favorable catalyst for the esterification reaction.

\subsection{Structural Analysis}

Figure 2 illustrates the XRD pattern of the EFB ${ }_{\text {MAC }}$ catalyst. The pattern exhibits broad diffraction peaks of $2 \theta$ at $20-70^{\circ}$ attributed to the amorphous carbon composed of aromatic carbon sheets. The diffraction peaks at $2 \theta=$ $24.5^{\circ}, 30.7^{\circ}, 33.6^{\circ}, 36.1^{\circ}, 43.8^{\circ}, 49.9^{\circ}, 54.4^{\circ}$, $57.7^{\circ}$, and $63.3^{\circ}$ for EFBMAC is assigned to (210), (220), (310), (311), (400), (421), (430), (511), and (440) indicate the formation of maghemite, the $\gamma-\mathrm{Fe}_{2} \mathrm{O}_{3}$ compound according to Inorganic Crystal Structure Database (ICSD: 98005-0297). It suggests that the iron oxidecomponents were successfully onto the EFB fiber in the impregnation process. It was consistent with the EDX results where iron particles were observed in the EFB $\mathrm{BAC}_{\mathrm{M}}$ catalyst. The formation of iron oxide also corresponded to the solid catalyst's magnetic property and separated using an external magnet [30]. According to the Debye-Scherrer formula, the average crys-

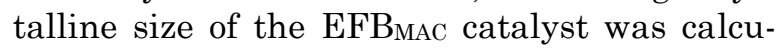
lated to be $30.31 \mathrm{~nm}$.

\subsection{Nitrogen Adsorption-Desorption Analysis}

The nitrogen $\left(\mathrm{N}_{2}\right)$ adsorption-desorption isotherm of EFB MAC $_{\text {catalyst is shown in Figure } 3 .}$ According to the finding, the EFBMAC had a high surface area of $188.87 \mathrm{~m}^{2} / \mathrm{g}$ and a pore vol-

Table 2. Elemental content of treated EFB fiber and EFBMAc.

\begin{tabular}{lcccc}
\hline \multirow{2}{*}{ Samples } & \multicolumn{4}{c}{ Elemental composition, wt\% } \\
\cline { 2 - 5 } & Carbon & Oxygen & Iron & Sulphur \\
\hline Treated EFB fibers & 57.76 & 42.24 & - & - \\
EFBMAC & 37.88 & 34.78 & 21.82 & 5.52 \\
\hline
\end{tabular}


ume of $0.1358 \mathrm{~cm}^{3} / \mathrm{g}$ with a single hysteresis loop. The presence of iron during the impregnation process results in porous structures, allowing active sites to be easily accessible to reactants. In a study reported by $\mathrm{Li}$ et al., the solid catalyst had a BET surface area of $92 \mathrm{~m}^{2} / \mathrm{g}$. The bulky ionic liquid molecules covered the precursor surface, resulting in a low surface area [31]. In another work, by Gardy et al. the BET surface area was observed between $49-78 \mathrm{~m}^{2} / \mathrm{g}$ after the coating of alumina and titanium oxide $\left(\mathrm{Al}-\mathrm{TiO}_{2}\right)$ particles [32]. Hence, it is suggested that the EFB fiber supported magnetic catalyst showed a high surface area and pore volume, which can be suitable as a catalyst and easily accessible to the reactants to produce high product yield [33,34].

\subsection{VSM Analysis}

The saturation magnetization of the magnetic catalyst was measured using VSM and the magnetic hysteresis loop presented in Figure 4. It was observed that the EFB shows superparamagnetic behavior with saturation magnetization of $24.97 \mathrm{emu} / \mathrm{g}$ after the

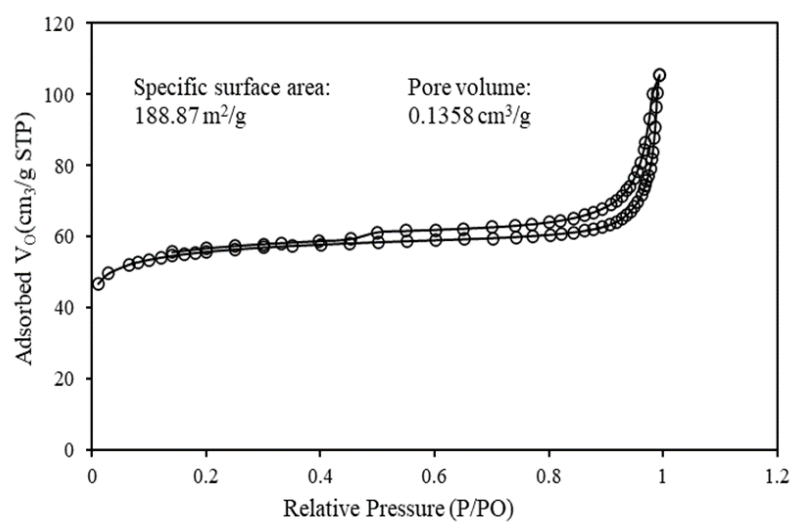

Figure $3 . \mathrm{N}_{2}$ adsorption-desorption isotherm of EFBMAC catalyst.

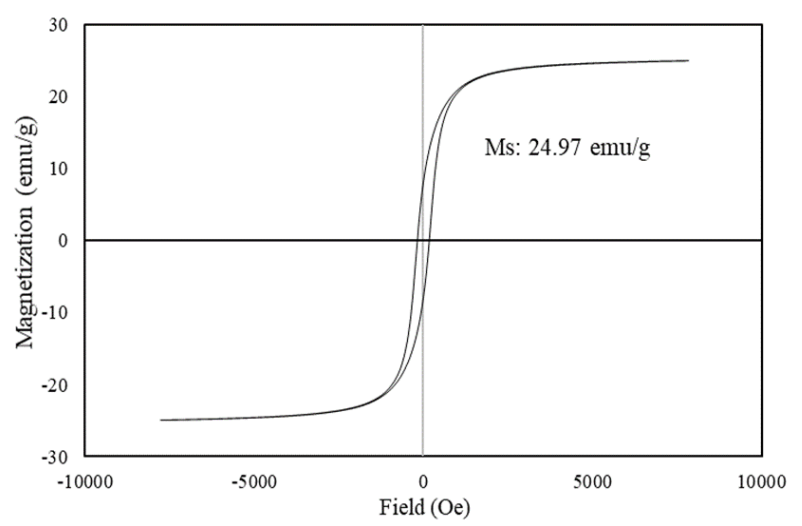

Figure 4. Hysteresis curve of EFBMAC catalyst. impregnation process and calcined at $500{ }^{\circ} \mathrm{C}$. It was reported by Wang et al. that a maximum of $20.5 \mathrm{Am}^{2} / \mathrm{kg}$ magnetism was observed in CMC-derived magnetic catalyst after calcined at $600{ }^{\circ} \mathrm{C}$ [35], and Chellapan et al. revealed a magnetism of $11.16 \mathrm{emu} / \mathrm{g}$ was obtained for cassava peel derived magnetic acid catalyst [36]. It indicates that EFB fiber can exhibit a high magnetization value and that the strong magnetism of the EFB MAC $_{\text {catalyst could assist }}$ in rapid recovery after the esterification reaction.

\subsection{FT-IR Analysis}

The functional groups in treated EFB fiber and EFBMAC catalyst were identified by FT-IR analysis, and FT-IR spectra were presented in Figure 5. The broad band at around $3328 \mathrm{~cm}^{-1}$ in the spectrum of treated EFB fiber corresponded to the hydroxyl groups $(\mathrm{O}-\mathrm{H})$ stretching vibration. The peak at $2898 \mathrm{~cm}^{-1}$ was attributed to the $\mathrm{C}-\mathrm{H}$ stretching vibration. While the bands at $1232 \mathrm{~cm}^{-1}$ and $890 \mathrm{~cm}^{-1}$ observed in treated fiber corresponded to the $\mathrm{C}-\mathrm{O}$ stretching vibration of cellulose. It was reported that the strong peak at $1024 \mathrm{~cm}^{-1}$ was assigned to the $\mathrm{C}-\mathrm{O}-\mathrm{C}$ pyranose ring skeletal vibration [37]. Comparing with treated EFB fiber, the characteristic peak of hydroxyl groups has not appeared in spectra of EFBMAC after the impregnation process. In the spectrum of EFBMAC, the appearance of absorption at 1612 $\mathrm{cm}^{-1}$ stretching vibration of $-\mathrm{COOH}$ groups was generated after the calcination process. Meanwhile, the two vibration bands at around $1110 \mathrm{~cm}^{-1}$ and $1026 \mathrm{~cm}^{-1}$ appeared due to the $\mathrm{O}=\mathrm{S}=\mathrm{O}$ symmetric stretching in $-\mathrm{SO}_{3} \mathrm{H}$ groups, indicate the treated EFB fiber was successfully impregnated with $-\mathrm{SO}_{3} \mathrm{H}$ groups. This result corresponded to the EDX result (Table 2), where the composition of sulfur and oxygen

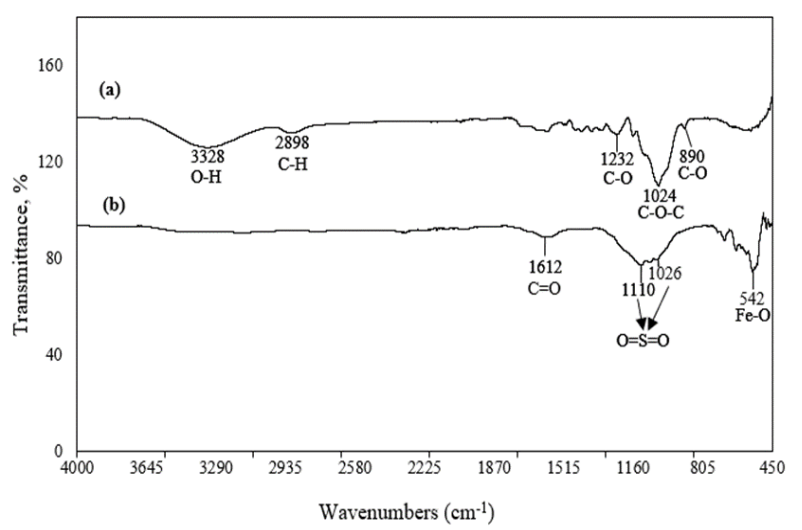

Figure 5. FT-IR spectra of (a) treated EFB

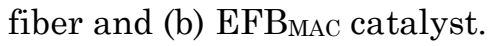


were identified in the catalyst. Thus, it indicates that EFBMAC catalyst consisted of polycyclic aromatic carbon sheets bearing $-\mathrm{SO}_{3} \mathrm{H}$ and $-\mathrm{COOH}$ groups. It was reported that the active sites composed of $-\mathrm{OH},-\mathrm{COOH}$ and $-\mathrm{SO}_{3} \mathrm{H}$ groups could enhance the reaction yield [38]. Furthermore, the existence of $\gamma-\mathrm{Fe}_{2} \mathrm{O}_{3}$ in the $\mathrm{EFB}_{\mathrm{MAC}}$ catalyst was attributed to the $\mathrm{Fe}-\mathrm{O}$ stretching band at $542 \mathrm{~cm}^{-1}$ was verified by XRD analysis (Figure 2).

3.8 Optimization of Methyl Oleate using Response Surface Methodology

\subsubsection{Model fitting and variance analysis}

Table 3 shows the experimental design, actual and predicted conversions resulted from the esterification reaction. The synthesized EFBMAC catalyst was used for the RSM optimization study to determine the optimized reaction conditions. The Box Behnken was designed with three factors (catalyst loading, methanol to oleic acid molar ratio and duration) at three levels for each factor. A total of 17 sets of experiments with different combinations were generated. According to the experimental results, the minimum esterification rate was $84.87 \%$, whereas a maximum esterification rate of $94.91 \%$ was recorded, as shown in Table 3. The quadratic equation model between the conversion rate and reaction factors was presented in Equation (4):

$$
\begin{aligned}
Y= & 93.24+3.55 A+1.48 B+0.82 C \\
& -0.57 A B-0.42 A C-0.13 B C \\
& -2.09 A^{2}-0.67 B^{2}-0.93 C^{2}
\end{aligned}
$$

$A, B$, and $C$ are the values of the catalyst loading, methanol to oleic acid molar ratio and duration, respectively, and $Y$ is the response of the esterification rate. The model's accuracy was determined based on the regression coefficient (Table 5) by determining the $\mathrm{R}^{2}$ value to be 0.9993 with more than $99.93 \%$ of output response significant to the quadratic model (Equation (4)), and the remaining 0.075 is produced from residues. The predicted $\mathrm{R}^{2}$ of 0.9983 is reasonably close to the expected $R^{2}$ of 0.9951. The model is expected to be a good fit with the regression coefficient value of more than $80 \%$ [39]. The correlation variation (C.V\%) obtained was $0.14 \%$ less than $10 \%$, and the lower C.V\% value indicates a good model fit [40]. As the esterification rate was examined using the Analysis of Variance (ANOVA), the statistical analysis revealed that the quadratic model is statistically significant. The p-value from the ANOVA table was used to evaluate the significance of each factor. The ANOVA results revealed that the model is significant, with an F-value of 1061.37 and a p-value of less than 0.0001, indicating that the model was statistically acceptable and significant with a p-value of less than 0.05. The ANOVA table indicates that all the factors $(A, B$ and $C)$ were

Table 3. Experimental design and results of the response surface analysis for esterification reaction (A: catalyst loading; B: methanol to oleic acid molar ratio; C: duration).

\begin{tabular}{ccccccc}
\hline \multirow{2}{*}{ Run } & \multicolumn{3}{c}{ Experimental Design } & & \multicolumn{2}{c}{ Esterification rate, \% } \\
\cline { 2 - 3 } \cline { 5 - 6 } & $\mathrm{A}$ & $\mathrm{B}$ & $\mathrm{C}$ & & Actual & Predicted \\
\hline 1 & 7 & $10: 1$ & 120 & & 93.30 & 93.24 \\
2 & 5 & $10: 1$ & 150 & & 87.88 & 87.91 \\
3 & 7 & $10: 1$ & 120 & & 93.30 & 93.24 \\
4 & 5 & $8: 1$ & 120 & & 84.90 & 84.87 \\
5 & 7 & $10: 1$ & 120 & & 93.30 & 93.24 \\
6 & 7 & $12: 1$ & 90 & & 92.42 & 92.42 \\
7 & 5 & $12: 1$ & 120 & & 88.91 & 88.98 \\
8 & 7 & $10: 1$ & 120 & & 93.30 & 93.24 \\
9 & 7 & $8: 1$ & 90 & & 89.11 & 89.21 \\
10 & 9 & $10: 1$ & 150 & & 94.10 & 94.17 \\
11 & 7 & $12: 1$ & 150 & & 93.90 & 93.81 \\
12 & 5 & $10: 1$ & 90 & & 85.49 & 85.42 \\
13 & 7 & $8: 1$ & 150 & & 91.11 & 91.11 \\
14 & 7 & $10: 1$ & 120 & & 93.30 & 93.24 \\
15 & 9 & $10: 1$ & 90 & & 93.40 & 93.37 \\
16 & 9 & $8: 1$ & 120 & & 93.19 & 93.12 \\
17 & 9 & $12: 1$ & 120 & & 94.91 & 94.94 \\
\hline
\end{tabular}


significant ( $p$-value $<0.05)$ with the model. The importance of the factors' interactive effects was also investigated. The findings revealed that all interactions $\left(A B, A C, A^{2}, B^{2}\right.$ and $\left.C^{2}\right)$ were significant to the model, except the methanol to oleic acid molar ratio with duration interaction $(B C)$. Hence, catalyst loading and methanol to oleic acid molar ratio considered the most significant factors that affect the esterification rate. The optimized reaction parameter conditions were as follows: $9 \mathrm{wt} \%$ catalyst loading, methanol to oleic acid molar ratio of $12: 1$ and reaction duration of $120 \mathrm{~min}$.

Figure 6 represents the Pareto chart for the Box-Behnken model. This chart indicates that the catalyst loading $(A)$, the methanol-to-oleic acid molar ratio $(B)$, duration $(C)$ and all interactions $\left(A B, A C, A^{2}, B^{2}\right.$ and $\left.C^{2}\right)$ were significant to the model and correlated to the ANOVA results.

3.8.2 Effect of reaction parameters on methyl oleate yield - response surface model

Catalyst loading, methanol to oleic acid molar ratio, and reaction duration are critical factors examined for methyl ester production to investigate the influence of independent factors on the esterification reaction. The interaction between the three reaction factors was investigated, and Design Expert Software (version 10.0.3) was used to generate three-dimensional (3D) surface model plots (Figure 7 a-c). Based on the $3 \mathrm{D}$ surface plots, the catalyst loading and the methanol to oleic acid molar ratio were discovered to be two crucial factors that influence the esterification process. Figure 7(a) shows a strong interaction between the catalyst loading and methanol to oleic acid molar ratio. From the plot, it can be seen that increasing the methanol to oleic acid molar ratio increases the esterification rate and lowers the acid value of oleic acid. It was reported that excess metha-

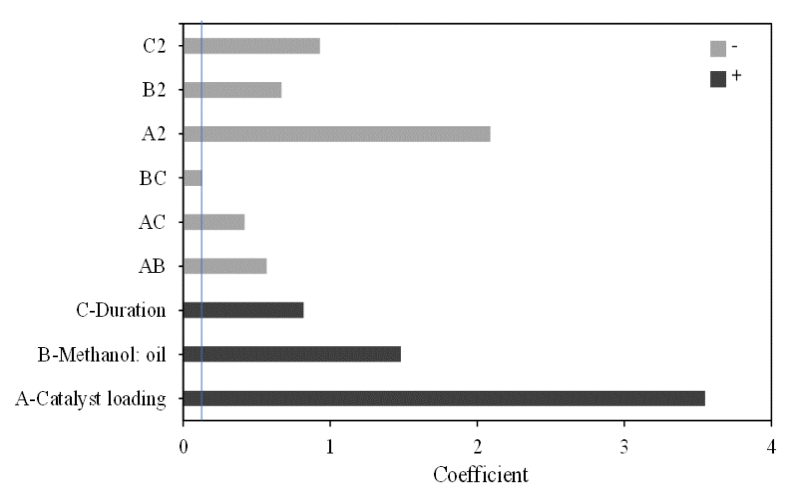

Figure 6. Pareto chart for the Box-Behnken model based on coefficient value. nol helps produce an equilibrium state in the reaction and disallow a reversible reaction in the esterification process [41,42]. The catalyst loading is considered as one of the influential reaction factors in the esterification process. Different percentage of catalyst loading was studied to distinguish its effect on methyl oleate production. The plot shows that at fixed re-
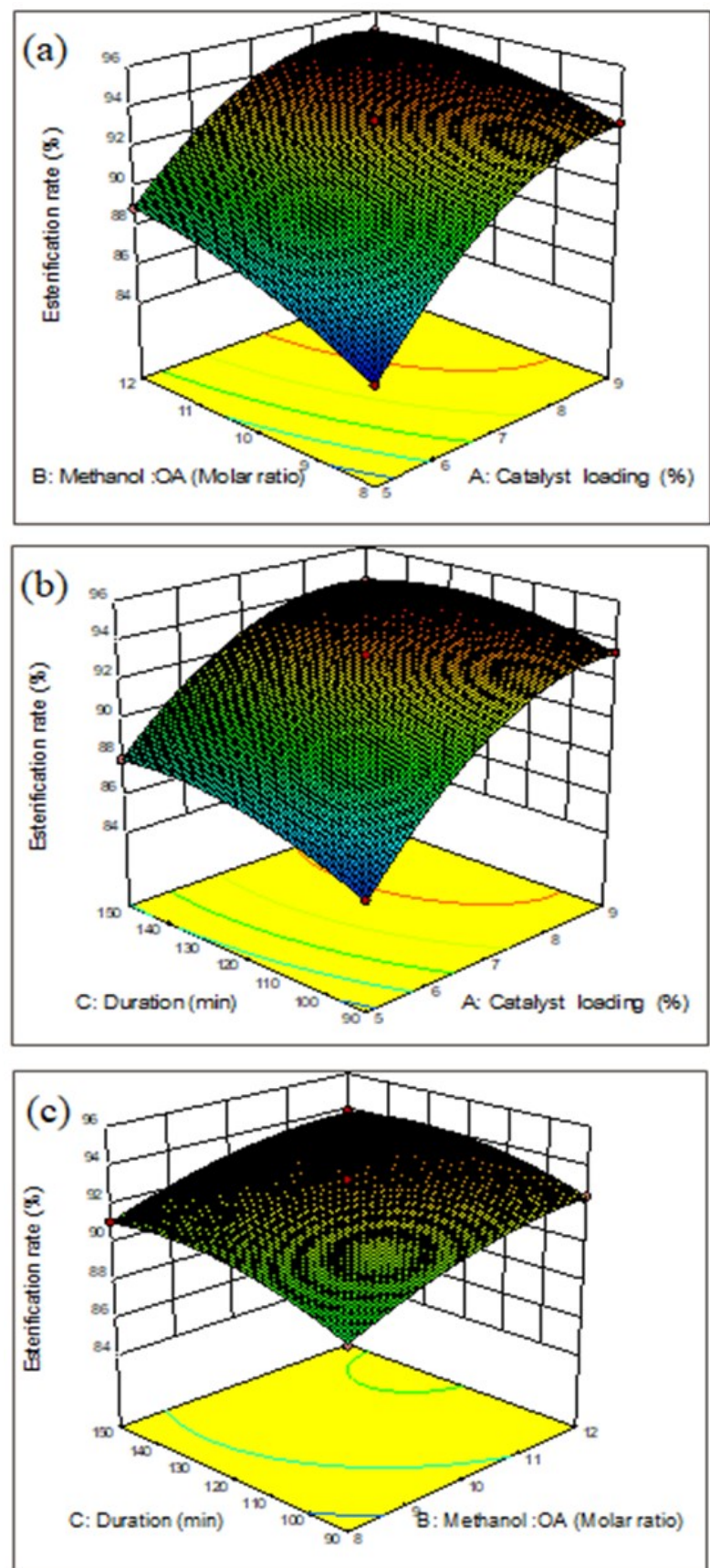

Figure 7. Surface regression 3D model on esterification rate (a) interaction between catalyst loading (wt\%) and methanol to oleic acid molar ratio, (b) interaction between catalyst loading (wt\%) and duration ( $\mathrm{min})$, and (c) interaction between methanol to oleic acid molar ratio and duration ( $\mathrm{min}$ ). 
action duration, the esterification rate increased with increasing catalyst loading from 5 wt $\%$ to $9 \mathrm{wt} \%$. Catalyst contributes to lowering the acid value of oleic acid, while the conversion of oleic acid to methyl oleate was enhanced with the help of methanol. A maximum esterification rate of $94.9 \%$ was achieved with $9 \mathrm{wt} \%$ catalyst loading and 12:1 of methanol to oleic acid molar ratio. In contrast, the minimum esterification rate was recorded with $84.9 \%$ at 5 wt $\%$ catalyst loading and methanol to oleic acid molar ratio of 8:1.

Figure 7(b) demonstrates the interaction between catalyst loading and reaction duration. The surface plot indicates an increment in esterification rate was observed at the highest catalyst loading and highest reaction duration. A sufficient amount of catalyst at appropriate duration is needed to achieve a higher esterification rate [43]. The highest esterification rate

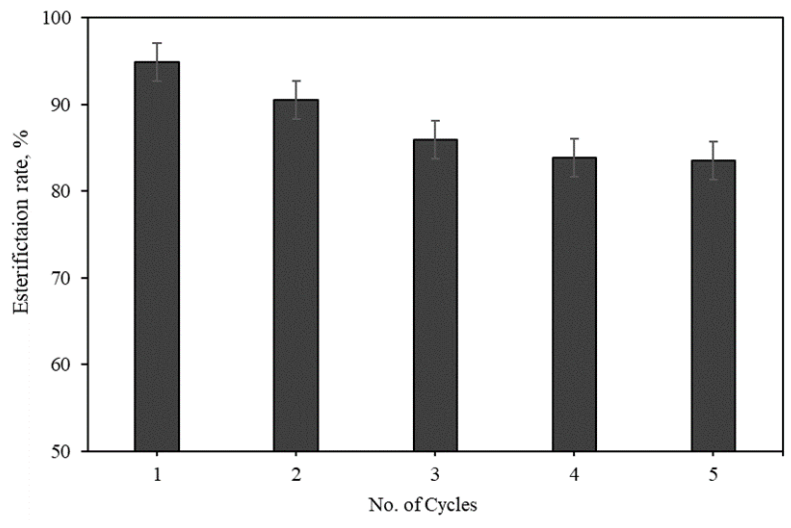

Figure 8. Recyclability of EFB MAC $_{\text {under opti- }}$ mized reaction conditions. of $94.1 \%$ was achieved at 9 wt $\%$ catalyst loading and $150 \mathrm{~min}$ reaction duration. However, the lowest esterification rate was reported at 5 $\mathrm{wt} \%$ catalyst loading and $90 \mathrm{~min}$ reaction duration with $85.5 \%$. Both the highest and lowest conversion was achieved at fixed methanol to oleic acid molar ratio of 10:1. A weak interaction was determined between the methanol to oil molar ratio and duration, as illustrated in Figure 7(c). It shows a slight increase in the esterification rate from 8:1 to 12:1 (methanol: oleic acid) and $90 \mathrm{~min}$ to $150 \mathrm{~min}$ (duration) with $89.1 \%$ to $93.9 \%$ at a fixed catalyst loading of 7 $\mathrm{wt} \%$. It suggests that the interaction between methanol and oleic acid molar ratio and reaction duration has minimal effect on the esterification rate. Overall, the trend of influential reaction factors on esterification reaction was observed to be the catalyst loading $>$ methanol to oleic acid molar ratio $>$ reaction duration based on the F-value (Table 4) with 6348.39, 1099.98 and 339.27 , respectively.

\subsection{Catalyst Recyclability}

The significant advantage of a heterogeneous catalyst is its reusability. To evaluate the reusability of the $\mathrm{EFB}_{\mathrm{MAC}}$, the recovered catalyst was able to be reused five times at the optimum reaction conditions. Figure 8 shows the obtained esterification rate for each cycle. According to the findings, the esterification rate has dropped from $94.9 \%$ to $85.9 \%$ in the $2^{\text {nd }} c y$ cle following the first esterification reaction. However, there was a slight reduction at the $4^{\text {th }}$ cycle to $83.9 \%$, and eventually, the esterification rate was stationary at the $5^{\text {th }}$ cycle with

Table 4. Analysis of Variance (ANOVA) for the quadratic model.

\begin{tabular}{lcccccc}
\hline & $\begin{array}{c}\text { Sum of } \\
\text { squares }\end{array}$ & DF & $\begin{array}{c}\text { Mean } \\
\text { square }\end{array}$ & F-value & p-value & \\
\hline Model & 151.92 & 9 & 16.88 & 1061.37 & $<0.0001$ & significant \\
A-Catalyst loading & 100.96 & 1 & 100.96 & 6348.39 & $<0.0001$ & \\
B-Methanol: oil & 17.49 & 1 & 17.49 & 1099.98 & $<0.0001$ & \\
C-Duration & 5.40 & 1 & 5.40 & 339.27 & $<0.0001$ & \\
$\mathrm{AB}$ & 1.31 & 1 & 1.31 & 82.44 & $<0.0001$ & \\
$\mathrm{AC}$ & 0.71 & 1 & 0.71 & 44.90 & 0.0003 & \\
$\mathrm{BC}$ & 0.07 & 1 & 0.07 & 4.25 & 0.0782 & \\
$\mathrm{~A}^{2}$ & 18.39 & 1 & 18.39 & 1156.47 & $<0.0001$ & \\
$\mathrm{~B}^{2}$ & 1.90 & 1 & 1.90 & 119.74 & $<0.0001$ & \\
$\mathrm{C}^{2}$ & 3.66 & 1 & 3.66 & 230.22 & $<0.0001$ & \\
\hline Residual & 0.11 & 7 & 0.02 & & & \\
Lack of Fit & 0.04 & 3 & 0.01 & 0.73 & 0.586 & not significant \\
Pure Error & 0.07 & 4 & 0.02 & & & \\
Cor Total & 152.03 & 16 & & & & \\
\hline
\end{tabular}

Note: $D F=$ degree of freedom 
a similar value. The decrease in the esterification rate has resulted from the leaching of active sites from the used catalyst during the esterification reaction. However, a lower degree of leaching was observed during the active site leaching test with esterification rate of $44 \%$. The leaching phase of EFBMAC was considered low and this correlated to the used catalyst acidity reduction to $2.1 \mathrm{mmol} / \mathrm{g}$ after 4 reaction cycles. This confirmed that the catalyst has minimal degree of leaching as the catalyst exhibited an esterification rate of more than $80 \%$ after $4^{\text {th }}$ cycle.

\section{Conclusion}

EFB fiber was utilized to produce an efficient biomass supported magnetic acid catalyst, which was effectively used in the esterification reaction of oleic acid with methanol. The catalyst has a high acid density with excellent magnetism, $24.97 \mathrm{~m}^{2} / \mathrm{g}$, and the catalyst can be recovered using a magnet. The Box-Behnken designing model was used to optimize the esterification process using the EFB MAC catalyst. The highest esterification rate of $94.9 \%$ was achieved with $\mathrm{R}^{2}=0.9993$ at optimum reaction conditions of $9 \mathrm{wt} \%$ catalyst loading, 12:1 methanol to oleic acid molar ratio for $120 \mathrm{~min}$ at 60 ${ }^{\circ} \mathrm{C}$. $\mathrm{EFB}_{\mathrm{MAC}}$ catalyst was discovered to be a promising catalyst with high catalytic proper- ties and reusability.

\section{Acknowledgement}

The authors are grateful for the Fundamental Research Grant Scheme (FRGS/1/2018/STG07/UNITEN/02/3) from the Ministry of Higher Education (MOHE) of Malaysia. We also appreciate the assistance and resources given by the UNITEN Institute for Sustainable Energy.

\section{References}

[1] Barbieri, L., Andreola, F., Lancellotti, I., Taurino, R. (2013). Management of agricultural biomass wastes: Preliminary study on characterization and valorisation in clay matrix bricks. Waste Manag., 33, 2307-2315. DOI: 10.1016/j.wasman.2013.03.014

[2] McKendry, P. (2002). Energy production from biomass (part 1): Overview of biomass. Bioresour. Technol., 83, 37-46. DOI: 10.1016/S0960-8524(01)00118-3

[3] Sansaniwal, S.K., Rosen, M.A., Tyagi, S.K. (2017). Global challenges in the sustainable development of biomass gasification: An overview. Renew. Sustain. Energy Rev., 80, 23-43. DOI: 10.1016/j.rser.2017.05.215

[4] Mohammad, N., Alam, M.Z., Kabbashi, N.A., Ahsan, A. (2012). Effective composting of oil palm industrial waste by filamentous fungi: A review. Resour. Conserv. Recycl., 58, 69-78. DOI: 10.1016/j.resconrec.2011.10.009

[5] Aziz, Z., Khan, M.J., Ling, T.P., Hassan, O., Maskat, M.Y. (2014). Effect of direct pretreatment using steam on the properties of oil palm empty fruit bunch. Der Pharma Chem., $6,1-6$.

Table 5. Statistical analysis of regression coefficient.

\begin{tabular}{lccc}
\hline \multicolumn{1}{c}{ Terms } & Coefficient & Standard error & t-Stat \\
\hline Intercept & 93.24 & 0.0564 & 93.37 \\
A-Catalyst loading & 3.55 & 0.0446 & 3.66 \\
B-Methanol: oleic acid & 1.48 & 0.0446 & 1.58 \\
C-Duration & 0.82 & 0.0446 & 0.93 \\
$\mathrm{AB}$ & -0.57 & 0.0631 & -0.42 \\
$\mathrm{AC}$ & -0.42 & 0.0631 & -0.27 \\
$\mathrm{BC}$ & -0.13 & 0.0631 & 0.02 \\
$\mathrm{~A}^{2}$ & -2.09 & 0.0615 & -1.94 \\
$\mathrm{~B}^{2}$ & -0.67 & 0.0615 & -0.53 \\
$\mathrm{C}^{2}$ & -0.93 & 0.0615 & -0.79 \\
\hline \multicolumn{1}{c}{ Statistical parameters } & Values & Statistical parameters & Values \\
\hline Standard deviation & 0.13 & $\mathrm{R}^{2}$ & 0.9993 \\
Mean & 91.5 & Adjusted R & 0.9983 \\
Coefficient if variation (C.V.\%) & 0.14 & Predicted R & 0.9951 \\
PRESS & 0.7417 & Adequate Precision & 104.04 \\
\hline
\end{tabular}


[6] Soltani, S., Rashid, U., Al-Resayes, S.I., Nehdi, I.A. (2017). Recent progress in synthesis and surface functionalization of mesoporous acidic heterogeneous catalysts for esterification of free fatty acid feedstocks: A review. Energy Convers. Manag., 141, 183-205. DOI: 10.1016/j.enconman.2016.07.042

[7] Martínez, S.L., Romero, R., Natividad, R., González, J. (2014). Optimization of biodiesel production from sunflower oil by transesterification using $\mathrm{Na}_{2} \mathrm{O} / \mathrm{NaX}$ and methanol. Catal. Today, 220-222, 12-20. DOI: 10.1016/j.cattod.2013.08.022

[8] Azócar, L., Ciudad, G., Heipieper, H.J., Navia, R. (2010). Biotechnological processes for biodiesel production using alternative oils. Appl. Microbiol. Biotechnol., 88, 621-636. DOI: 10.1007/s00253-010-2804-z

[9] Kumar Tiwari, A., Kumar, A., Raheman, H. (2007). Biodiesel production from jatropha oil (Jatropha curcas) with high free fatty acids: An optimized process. Biomass and Bioenerg $y, \quad 31, \quad 569-575$. D O I : 10.1016/j.biombioe.2007.03.003

[10] Lourinho, G., Brito, P. (2015). Advanced biodiesel production technologies: novel developments. Rev. Environ. Sci. Biotechnol., 14, 287-316. DOI: 10.1007/s11157-014-9359-x

[11] Talebian-Kiakalaieh, A., Amin, N.A.S., Mazaheri, H. (2013). A review on novel processes of biodiesel production from waste cooking oil. Appl. Energy, 104, 683-710. DOI: 10.1016/j.apenergy.2012.11.061

[12] Vieira, S.S., Magriotis, Z.M., Ribeiro, M.F., Graça, I., Fernandes, A., Lopes, J.M.F.M., Saczk, A.A. (2015). Use of HZSM-5 modified with citric acid as acid heterogeneous catalyst for biodiesel production via esterification of oleic acid. Microporous Mesoporous Mater., $201, \quad 160-168$. D O I : 10.1016/j.micromeso.2014.09.015

[13] Abdullah, S.H.Y.S., Hanapi, N.H.M., Azid, A., Umar, R., Juahir, H., Khatoon, H., Endut, A. (2016). A review of biomass-derived heterogeneous catalyst for a sustainable biodiesel production. Renew. Sustain. Energy Rev., $70, \quad 10400-1051$. D O I : 10.1016/j.rser.2016.12.008

[14] Liu, X.Y., Huang, M., Ma, H.L., Zhang, Z.Q., Gao, J.M., Zhu, Y.L., Guo, X.Y. (2010). Preparation of a carbon-based solid acid catalyst by sulfonating activated carbon in a chemical reduction process. Molecules, 15, 7188-7196. DOI: 10.3390/molecules15107188
[15] Alaei, S., Haghighi, M., Toghiani, J., Rahmani Vahid, B. (2018). Magnetic and reusable $\mathrm{MgO} / \mathrm{MgFe}_{2} \mathrm{O}_{4}$ nanocatalyst for biodiesel production from sunflower oil: Influence of fuel ratio in combustion synthesis on catalytic properties and performance. Ind. Crops Prod., $117, \quad 322-332$. D O I : 10.1016/j.indcrop.2018.03.015

[16] Zhang, F., Tian, X.F., Fang, Z., Shah, M., Wang, Y.T., Jiang, W., Yao, M. (2017). Catalytic production of Jatropha biodiesel and hydrogen with magnetic carbonaceous acid and base synthesized from Jatropha hulls. Energy Convers. Manag., 142, 107-116. DOI: 10.1016/j.enconman.2017.03.026

[17] Hu, S., Guan, Y., Wang, Y., Han, H. (2011). Nano-magnetic catalyst $\mathrm{KF} / \mathrm{CaO}-\mathrm{Fe}_{3} \mathrm{O}_{4}$ for biodiesel production. Appl. Energy, 88, 26852690. DOI: 10.1016/j.apenergy.2011.02.012

[18] Araujo, R.O., Santos, V.O., Ribeiro, F.C.P., Chaar, J.d.S., Pereira, A.M., Falcão, N.P.S., de Souza, L.K.C. (2021). Magnetic acid catalyst produced from acai seeds and red mud for biofuel production. Energy Convers. Manag., 228, 113636 . DO I : 10.1016/j.enconman.2020.113636

[19] Zhou, Y., Niu, S., Li, J. (2016). Activity of the carbon-based heterogeneous acid catalyst derived from bamboo in esterification of oleic acid with ethanol. Energy Convers. Manag., $114, \quad 188-196 . \quad$ D O I : 10.1016/j.enconman.2016.02.027

[20] Pan, H., Liu, X., Zhang, H., Yang, K., Huang, S., Yang, S. (2017). Multi- $\mathrm{SO}_{3} \mathrm{H}$ functionalized mesoporous polymeric acid catalyst for biodiesel production and fructose-to-biodiesel additive conversion. Renew. Energy, 107, 245-252. DOI: 10.1016/j.renene.2017.02.009

[21] Shu, Q., Zou, W., He, J., Lesmana, H., Zhang, C., Zou, L., Wang, Y. (2019). Preparation of the $\mathrm{F}-\mathrm{SO}_{4}{ }^{2-/ M W C N T s}$ catalyst and kinetic studies of the biodiesel production via esterification reaction of oleic acid and methanol. Renew. Energy, 135, 836-845. DOI: 10.1016/j.renene.2018.12.067

[22] Wang, A., Wang, J., Lu, C., Xu, M., Lv, J., $\mathrm{Wu}$, X. (2018). Esterification for biofuel synthesis over an eco-friendly and efficient kaolinite-supported $\mathrm{SO}_{4}{ }^{2-} / \mathrm{ZnAl}_{2} \mathrm{O}_{4}$ macroporous solid acid catalyst. Fuel, 234, 430-440. DOI: 10.1016/j.fuel.2018.07.041

[23] Deeba, F., Kumar, B., Arora, N., Singh, S., Kumar, A., Han, S.S., Negi, Y.S. (2020). Novel bio-based solid acid catalyst derived from waste yeast residue for biodiesel production. Renew. Energy, 159, 127-139. DOI: 10.1016/j.renene.2020.05.029 
[24] Dechakhumwat, S., Hongmanorom, P., Thunyaratchatanon, C., Smith, S.M., Boonyuen, S., Luengnaruemitchai, A. (2020). Catalytic activity of heterogeneous acid catalysts derived from corncob in the esterification of oleic acid with methanol. Renew. Energy, 148, 897-906. DOI: $10.1016 /$ j.renene.2019.10.174

[25] Chang, B., Li, Y., Guo, Y., Yang, B. (2016). Simple fabrication of magnetically separable mesoporous carbon sphere with excellent catalytic performance for biodiesel production. $J$. Taiwan Inst. Chem. Eng., 60, 241-246. DOI: 10.1016/j.jtice.2015.10.009

[26] Ibrahim, Z., Aziz, A.A., Ramli, R., Jusoff, K., Ahmad, M., Jamaludin, M.A. (2015). Effect of treatment on the oil content and surface morphology of oil palm (Elaeis guineensis) empty fruit bunches (EFB) fibres. Wood Res., 60, 157-166.

[27] Rosli, N.S., Harun, S., Jahim, J.M., Othaman, R. (2017). Chemical and Physical Characterization of Oil Palm Empty Fruit Bunch. Malaysian J. Anal. Sci., 21, 188-196. DOI: 10.17576/mjas-2017-2101-22

[28] Palamae, S., Dechatiwongse, P., Choorit, W., Chisti, Y., Prasertsan, P. (2017). Cellulose and hemicellulose recovery from oil palm empty fruit bunch (EFB) fibers and production of sugars from the fibers. Carbohydr. Polym., 155, 491-497. DOI: 10.1016/j.carbpol.2016.09.004

[29] Hamzah, F., Idris, A., Shuan, T.K. (2011). Preliminary study on enzymatic hydrolysis of treated oil palm (Elaeis) empty fruit bunches fibre (EFB) by using combination of cellulase and 8 1-4 glucosidase. Biomass and Bioenergy, $35, \quad 1055-1059$. D O I : 10.1016/j.biombioe.2010.11.020

[30] Chen, T., Peng, L., Yu, X., He, L. (2018). Magnetically recyclable cellulose-derived carbonaceous solid acid catalyzed the biofuel 5ethoxymethylfurfural synthesis from renewable carbohydrates. Fuel, 219, 344-352. DOI: 10.1016/j.fuel.2018.01.129

[31] Li, J., Liang, X. (2017). Magnetic solid acid catalyst for biodiesel synthesis from waste oil. Energy Convers. Manag., 141, 126-132. DOI: 10.1016/j.enconman.2016.06.072

[32] Gardy, J., Osatiashtiani, A., Céspedes, O., Hassanpour, A., Lai, X., Lee, A.F., Wilson, K., Rehan, M. (2018). A magnetically separable $\mathrm{SO}_{4} / \mathrm{Fe}-\mathrm{Al}-\mathrm{TiO}_{2}$ solid acid catalyst for biodiesel production from waste cooking oil. Appl. Catal. B Environ., 234, 268-278. DOI: 10.1016/j.apcatb.2018.04.046.
[33] Wang, Y.T., Fang, Z., Yang, X.X., Yang, Y.T., Luo, J., Xu, K., Bao, G.R. (2018). One-step production of biodiesel from Jatropha oils with high acid value at low temperature by magnetic acid-base amphoteric nanoparticles. Chem. Eng. J., 348, 929-939. DOI: 10.1016/j.cej.2018.05.039

[34] Xie, W., Han, Y., Wang, H. (2018). Magnetic $\mathrm{Fe}_{3} \mathrm{O}_{4} / \mathrm{MCM}-41$ composite-supported sodium silicate as heterogeneous catalysts for biodiesel production. Renew. Energy, 125, 675681. DOI: 10.1016/j.renene.2018.03.010

[35] Wang, Anping, Li, H., Pan, H., Zhang, H., Xu, F., Yu, Z., Yang, S. (2018). Efficient and green production of biodiesel catalyzed by recyclable biomass-derived magnetic acids. Fuel Process. Technol., 181, 259-267. DOI: 10.1016/j.fuproc.2018.10.003

[36] Chellappan, S., Aparna, K., Chingakham, C., Sajith, V., Nair, V. (2019). Microwave assisted biodiesel production using a novel Brönsted acid catalyst based on nanomagnetic biocomposite. Fuel, 246, 268-276. DOI: 10.1016/j.fuel.2019.02.104

[37] Islam, M.S., Kao, N., Bhattacharya, S.N., Gupta, R., Bhattacharjee, P.K. (2017). Effect of low pressure alkaline delignification process on the production of nanocrystalline cellulose from rice husk. J. Taiwan Inst. Chem. Eng., $80, \quad 820-834$. D O I : 10.1016/j.jtice.2017.06.042

[38] Zhang, F., Tian, X., Shah, M., Yang, W. (2017). Synthesis of magnetic carbonaceous acids derived from hydrolysates of Jatropha hulls for catalytic biodiesel production. RSC Adv. , 7, 11403-11413. DOI: 10.1039/c6ra28796d

[39] Marwaha, A., Rosha, P., Mohapatra, S.K., Mahla, S.K., Dhir, A. (2019). Biodiesel production from Terminalia bellerica using eggshell-based green catalyst: An optimization study with response surface methodology. Energy Reports, 5, 1580-1588. DOI: 10.1016/j.egyr.2019.10.022

[40] Singh, V., Belova, L., Singh, B., Sharma, Y.C. (2018). Biodiesel production using a novel heterogeneous catalyst, magnesium zirconate $\left(\mathrm{Mg}_{2} \mathrm{Zr}_{5} \mathrm{O}_{12}\right)$ : Process optimization through response surface methodology (RSM). Energy Convers. Manag., 174, 198-207. DOI: 10.1016/j.enconman.2018.08.029

[41] Trombettoni, V., Lanari, D., Prinsen, P., Luque, R., Marrocchi, A., Vaccaro, L. (2018). Recent advances in sulfonated resin catalysts for efficient biodiesel and bio-derived additives production. Prog. Energy Combust. Sci., 65, 136-162. DOI: 10.1016/j.pecs.2017.11.001 
[42] Boz, N., Degirmenbasi, N., Kalyon, D.M. (2015). Esterification and transesterification of waste cooking oil over Amberlyst 15 and modified Amberlyst 15 catalysts. Appl. Catal. $B$ Environ., 165, 723-730. DOI: 10.1016/j.apcatb.2014.10.079
[43] Ishola, N.B., Adeyemi, O.O., Adesina, A.J., Odude, V.O., Oyetunde, O.O., Okeleye, A.A., Betiku, E. (2017). Adaptive neuro-fuzzy inference system-genetic algorithm vs. response surface methodology: A case of optimization of ferric sulfate-catalyzed esterification of palm kernel oil. Process Saf. Environ. Prot., $111, \quad 211-220$. D O I : 10.1016/j.psep.2017.07.004 